\title{
MRI CAUDATE AND CINGULATE VOLUMETRIC CHANGES RELATED TO ADHD TREATMENT
}

Caudate and anterior cingulate cortex (ACC) volumes, measured by structural MRI, were compared in children with $\mathrm{ADHD}$, previously treated and untreated, and controls, in a study at the University of Texas, San Antonio and Austin; and researchers from the UK and Canada. Caudates were smaller bilaterally in both ADHD groups compared to controls. The right $\mathrm{ACC}$ was significantly smaller in the ADHD-treatment naïve $(-\mathrm{TN})$ group compared to the ADHD-treated and control groups. In contrast, the left ACC showed no significant difference in size among the 3 groups; however, it was smaller in the ADHD-TN group compared to controls $(\mathrm{p}=0.07)$. Smaller left caudate volume was associated with more restlessness/impulsivity on the parent Conners scale for ADHD groups. Smaller caudates bilaterally were found in children with $\mathrm{ADHD}$, and smaller caudates were associated with inattention on the Behavior Assessment Parent scale. Volume of ACC was not related to attention scores. (Pliszka SR, Lancaster J, Liotti M, Semrud-Clikeman M. Volumetric MRI differences in treatment-naïve vs chronically treated children with ADHD. Neurology (September 2 of 2) 2006;67:1023-1027). (Reprints: Dr Margaret Semrud-Clikeman, University Station, D 5800, University of Texas, Austin, TX 78712).

COMMENT. Caudate and anterior cingulate volumes are different in children with ADHD-combined type compared to controls. Parent-rated behavioral measures of attention and response inhibition are correlated with caudate, but not cingulate, size in ADHD patients. Restless/impulsive behavior is correlated with a smaller left caudate, whereas inattentiveness is associated with bilateral caudate volume reduction. A small right cingulate is a feature of untreated ADHD children compared to those treated and normal controls, whereas the left cingulate shows no significant difference in ADHD patients, treated or untreated, and controls. Long-term stimulant therapy for ADHD may be expected to normalize ACC volume.

\section{EFFECTS OF OROS-MPH VERSUS DL-AMPHETAMINE-XR ON DRIVING PERFORMANCE OF ADHD ADOLESCENTS}

Driving performance of 35 adolescent ADHD patients (19 boys/16 girls; mean age 17.8 years) on a driving simulator was compared while taking OROS methylphenidate (Concerta, $72 \mathrm{mg}$ ), mixed dl-amphetamine salts (Adderall XR, $30 \mathrm{mg}$ ), or placebo in a randomized, double-blind, crossover study at University of Virginia, Charlottesville. Both treatments led to better overall driving performance. A comparison of treatments showed that Concerta was associated with significantly better driving peformance than placebo or Adderall XR, and resulted in better steering (less driving across midline and off road), better speed control (less speeding and less erratic speeds), and less impulsive driving (less inappropriate breaking and indecision at intersections and left turns). Comparing driving performance tested at 5,8, and $11 \mathrm{PM}$, the worst performance occurred at $8.00 \mathrm{PM}$, and the best performance for both Concerta and Adderall XR was at 11.00 PM, 15 hours after taking the medication. Participants' subjective ratings were not significantly different from the 